\title{
Produtividade e qualidade de frutos de videira 'Isabel' em função das doses de etefon e épocas de poda
}

\author{
Camila Meira Abreu ${ }^{1}$, Luiz Fernandes Cardoso Campos ${ }^{2}$, Diego Palmiro Ramirez Ascheri ${ }^{1}$, \\ Alexsander Seleguini ${ }^{2}$ \\ ${ }^{1}$ Universidade Estadual de Goiás, - UEG. Câmpus de Anápolis, GO, Brasil. E-mail: camilaabreuagro@ hotmail.com, \\ ascheridpr@gmail.com \\ ${ }^{2}$ Universidade Federal de Goiás - UFG, Goiânia, GO, Brasil. E-mail: luizfernandescampos@hotmail.com, aseleguini@gmail.com
}

Recebido: 24/06/2016; Aceito: 16/11/2016.

\section{RESUMO}

A videira em região tropical necessita de cuidados diferenciados, quando comparada às regiões de clima temperado, principalmente em relação ao manejo da copa. Objetivou-se com este trabalho avaliar a produtividade e a qualidade dos frutos, influenciados por diferentes épocas de poda aliadas a doses de Ethephon, em duas safras da videira Isabel. O delineamento foi inteiramente casualizado, com dezesseis tratamentos no esquema fatorial $4 \mathrm{x}$ 4, com quatro repetições. O primeiro fator foi composto pelas épocas de poda: na safra de inverno ( $08 /$ março, 22/março, 05/abril e 19/abril de 2013); na safra de verão (25/agosto, 08/setembro, 22/setembro e 06/outubro de 2013). O segundo fator consistiu em quatro concentrações de Ethephon $\left(0,720,1440,2160 \mathrm{mg}\right.$ i.a. $\left.\mathrm{L}^{-1}\right)$. Na safra de inverno a época de poda -05 de abril, alcançou a maior produtividade $\left(1852 \mathrm{~kg} \mathrm{ha}^{-1}\right)$, com relação às doses de Ethephon; a produtividade apresentou crescimento linear, com aumento das doses. A poda de 05 de abril também se destacou na qualidade dos frutos. Na safra de verão a poda de 22 de março culminou na maior produtividade $\left(9046 \mathrm{~kg} \mathrm{ha}^{-1}\right)$ e melhor qualidade dos frutos. As doses de Etefon não influenciaram a produtividade e qualidade dos frutos, para esta safra.

Palavras-chave: Vitis labrusca L., características qualitativas, tratos culturais, viticultura tropical.

\section{Productivity and quality of 'Isabel' vine fruit in function of etefon doses and pruning times}

\begin{abstract}
The vine in tropical region needs special care when compared to temperate regions, especially regarding the handling of the canopy. The objective of this study was to evaluate the productivity and fruit quality, influenced by different pruning times combined with Ethephon doses in two crops of Isabel vine. The design was completely randomized, with sixteen treatments in a factorial $4 \times 4$, with four replications. The first factor was composed of the pruning times: in the winter season (March 08; March 22; April 05 and April 19, 2013); the summer harvest (August 25; September 08; September 22 and October 06, 2013). The second factor consisted of four Ethephon concentrations $\left(0,720,1440,2160 \mathrm{mg}\right.$ i.a. $\left.\mathrm{L}^{-1}\right)$. In the winter season the pruning time, April 05, 2013 reached the highest yield (1852 $\left.\mathrm{kg} \mathrm{ha}^{-1}\right)$ with respect to doses of Ethephon productivity showed a linear growth with increasing doses. Pruning April 05, 2013 also stood out on fruit quality. The summer harvest pruning March 22, 2013 resulted in increased productivity $\left(9046 \mathrm{~kg} \mathrm{ha}^{-1}\right)$ and better fruit quality. Doses of Ethephon did not influence the productivity and fruit quality, for this crop.
\end{abstract}

Key words: Vitis labrusca L., qualitative characteristics, cultural practices, tropical viticulture. 


\section{Introdução}

Os principais polos de viticultura tropical no Brasil são o Vale do Submédio São Francisco, o noroeste Paulista e o norte de Minas Gerais. Nos últimos anos, a viticultura tropical expandiu-se por vários outros Estados, como Espírito Santo, Mato Grosso do Sul, Mato Grosso, Goiás, Rondônia, Ceará e Piauí (Camargo et al., 2011). Segundo dados do ano de 2015, a área plantada com videira em Goiás foi de 150 ha, com uma produção total de 3.942 toneladas e produtividade média de $26.280 \mathrm{~kg} \mathrm{ha}^{-1}$ (IBGE, 2016).

A expansão da viticultura brasileira tem levado os produtores cada vez mais a se adequarem às novas técnicas e manejo da cultura, sobretudo com uso de tecnologias envolvendo os tratos culturais, evidenciando neste caso a realização de épocas de poda. Estas podem ser determinantes em uma safra, uma vez que é a partir da poda que se inicia o ciclo produtivo da videira. As videiras em clima tropical oferecem a possibilidade de poda a qualquer época do ano, pela inexistência de frio hibernal. Entretanto, necessita de tratos culturais adequados, como adubação, irrigação e também da alternância de podas entre longa e curta (Silva et al., 2006).

O conhecimento da melhor época de poda é importante para o planejamento da colheita pois a poda influencia o ciclo da cultura, que pode se diferenciar ao longo do ano (Bardin et al., 2010). Outro ponto a ser observado é a busca de períodos de clima seco para produção da safra principal, sendo menos propicio a incidência de doenças fúngicas. $\mathrm{O}$ míldio da videira (Plasmopara viticola), severa doença, pode causar elevados prejuízos e ataca todas as cultivares comercialmente importantes (Boubakri et al., 2012). O clima seco também proporciona colheita de frutos com melhor qualidade fico-química. No período das águas o risco de doenças é grande, elevando as perdas e elevando os custos de produção para o controle fitossanitário dos vinhedos (Camargo e Protas, 2011).

$\mathrm{O}$ Etefon tem sido usado como um produto eficaz para aumento de brotação de gemas em condições tropicais (Schenato et al., 2007). Aplicações sucessivas em videiras provocam o aumento da fertilidade e estimulam a brotação das gemas de ciclos anteriores, aumentando a produtividade da cultura (Fracaro et al., 2004a; Fracaro at al., 2004b). Além disso, a aplicação via foliar de Etefon em videiras tem sido eficaz quanto ao aumento do crescimento e diâmetro dos ramos e no aumento do comprimento, largura e peso dos cachos (Pereira; Fracaro, 2004).

Dentre os diversos efeitos que a alteração da época de poda e da utilização de Etefon podem promover no sistema produtivo da videira está a alteração das qualidades físico-químicas dos frutos (Fracaro et al., 2004a; Pereira; Fracaro, 2004), evidenciada pela análise do teor de sólidos solúveis, $\mathrm{pH}$ e acidez titulável além do crescimento vegetativo. Objetivou-se com este trabalho avaliar a produtividade e a qualidade dos frutos, influenciados por diferentes épocas de poda aliadas a doses de Etefon, em duas safras da videira Isabel.

\section{Material e Métodos}

O experimento foi realizado no município de Itapuranga, GO, na Fazenda Capoeira Grande, com coordenadas geográficas $15^{\circ} 34^{\prime} 32^{\prime}$ ' latitude S, 50 00' 31 " longitude W e altitude média de $635 \mathrm{~m}$.

De acordo com a classificação de Koppen, o clima predominante na região é do tipo Aw (clima tropical com estação seca de inverno). $O$ solo da área experimental foi classificado como Latossolo Vermelho distrófico (Embrapa, 2013), cujas características químicas e físicas antes da instalação do experimento, na camada de $0 \mathrm{~cm}$ a $20 \mathrm{~cm}$ de profundidade foram: $\mathrm{pH}$ em $\mathrm{CaCl}_{2}=6,2 ;$ M.O. $=38 \mathrm{~g} \mathrm{dm}^{-3} ;$ P-Mehlich $=3,8 \mathrm{mg}$ $\mathrm{dm}^{-3} ; \mathrm{Al}=0,0 \mathrm{cmol}_{\mathrm{c}} \mathrm{dm}^{-3} ; \mathrm{H}+\mathrm{Al}=1,7 \mathrm{cmol}_{\mathrm{c}} \mathrm{dm}^{-3} ; \mathrm{K}=$ $0,27 \mathrm{cmol}_{\mathrm{c}} \mathrm{dm}^{-3} ; \mathrm{Ca}=5,6 \mathrm{cmol}_{\mathrm{c}} \mathrm{dm}^{-3} ; \mathrm{Mg}=2,6 \mathrm{cmol}_{\mathrm{c}}$ $\mathrm{dm}^{-3} ; \mathrm{S}=8,47 \mathrm{cmol}_{\mathrm{c}} \mathrm{dm}^{-3} ; \mathrm{CTC}=9,2 \mathrm{cmol}_{\mathrm{c}} \mathrm{dm}^{-3} ; \mathrm{V}=$ $81,5 \%$; argila $=440 \mathrm{~g} \mathrm{~kg}^{-1}$; silte $=180 \mathrm{~g} \mathrm{~kg}^{-1}$ e areia $=$ $380 \mathrm{~g} \mathrm{~kg}^{-1}$.

Os dados climáticos da região foram obtidos de estação meteorológica da Cidade de Goiás, GO, no ano de 2013 e início de 2014. (Figura 1). O Experimento foi instalado em um parreiral, com dois anos de idade após a enxertia de videira 'Isabel', enxertada sobre o portaenxerto IAC 572 'Jales', irrigado por microaspersão, em sistema de condução tipo latada, no espaçamento de 2,5 $\mathrm{m} \times 2,5 \mathrm{~m}$.

Foram conduzidos dois experimentos, aqui denominados de safra de inverno e safra de verão, na mesma área com as mesmas plantas. $\mathrm{O}$ experimento chamado de "safra de inverno" foi iniciado em fevereiro e finalizado em agosto de 2013, o experimento chamado de safra de verão foi de agosto de 2013 até fevereiro de 2014.

$\mathrm{Na}$ safra de inverno as videiras foram submetidas à poda longa, ou poda de produção, mantendo cinco gemas por vara. Na safra de verão, as videiras foram submetidas à poda curta, ou poda de renovação, mantendo-se duas gemas por vara.

$\mathrm{Na}$ ocasião da colheita foi avaliada a produtividade e as variáveis associadas: número de cachos por planta, massa média de cacho, comprimento e largura de cacho, número de bagas por cacho, comprimento, largura e massa de baga. 


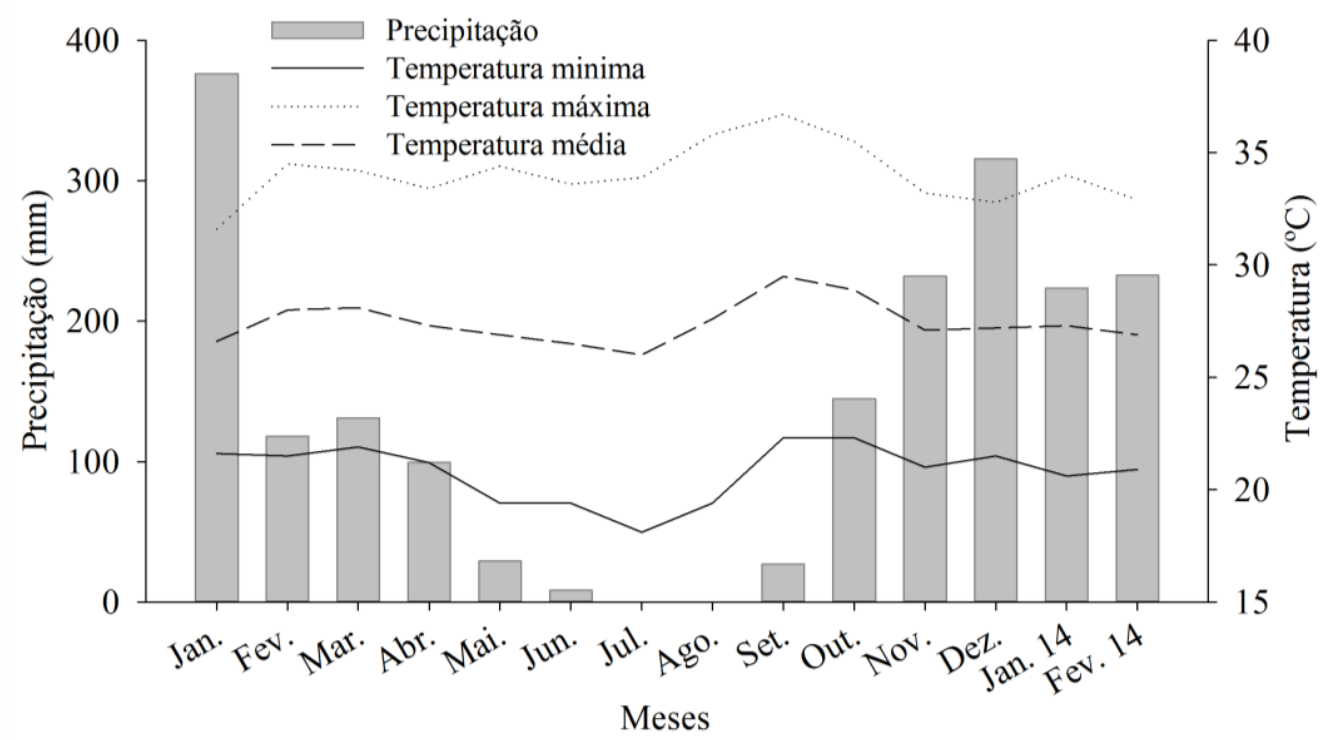

Figura 1 - Precipitação pluviométrica, temperatura máxima, mínima e média mensais, no período do experimento (2013/2014), dados obtidos em estação de aquisição automática de dados. Fonte: INMET/Estação Meteorológica da Cidade de Goiás, 2014.

Em cada safra, foram realizados dezesseis tratamentos estabelecidos em delineamento de blocos casualizados, no esquema fatorial $4 \times 4$, com quatro repetições. Cada parcela continha uma planta de videira, num total de 64 plantas $\left(400 \mathrm{~m}^{2}\right)$. O primeiro fator foi composto pelas épocas de poda a saber: na safra de inverno (08/março, 22/março, 05/abril e 19/abril de 2013); na safra de verão (25/agosto, 8/setembro, 22/setembro e 06/outubro de 2013). O segundo fator consistiu em quatro concentrações de Etefon (0, 720, 1440, $2160 \mathrm{mg} \mathrm{L}^{-1}$ ). Foi utilizado o produto comercial Ethrel $^{\circledR}$ na concentração de $240 \mathrm{~g} \mathrm{~L}^{-1}$ de Etefon; as concentrações estudadas foram: metade da dose recomendada (720 $\mathrm{mg} \mathrm{L}^{-1}$ ), a dose recomendada (1440 $\mathrm{mg} \mathrm{L}^{-1}$ ) e duas vezes a dose recomendada (2160 $\left.\mathrm{mg} \mathrm{L}^{-1}\right)$ (Fracaro et al., 2004a). O produto foi diluído em água, e aplicado sobre as plantas enfolhadas, com pulverizador costal até o ponto de escorrimento $(1000 \mathrm{~L}$ de calda ha ${ }^{1}$ ). A aplicação foi realizada vinte dias antes de cada poda. Após cada poda, realizou-se a superação da dormência, das gemas, com Cianamida hidrogenada $\left(\right.$ Dormex $^{\circledR}$, a $5 \%$ ), por meio de pincelamento com rolo de espuma. A adubação no parreiral utilizada pelo produtor na safra de inverno foi: $35 \mathrm{~g}$ planta de $\mathrm{P}_{2} \mathrm{O}_{5}$ (superfosfato simples) dez dias antes da poda; $20 \mathrm{~g}$ planta $^{-1}$ de $\mathrm{N}$ (ureia) aos quinze e 45 dias após a poda; $25 \mathrm{~g}_{\text {planta }}{ }^{-1}$ de FTE BR12 aos quinze dias após a poda e $15 \mathrm{~g}_{\text {planta }}{ }^{-1}$ de $\mathrm{K}_{2} \mathrm{O}$, (cloreto de potássio) aos oitenta dias após a poda. A adubação na safra de verão foi: 8 , 60 e 20 g planta $^{-1}$ de $\mathrm{N}, \mathrm{P}_{2} \mathrm{O}_{5}$ e $\mathrm{K}_{2} \mathrm{O}$, respectivamente. Como fonte o formulado 4-30-10, dez dias antes da poda; $20 \mathrm{~g} \mathrm{planta}^{-1}$ de $\mathrm{N}$ (ureia) aos quinze e 45 dias após a poda e $15 \mathrm{~g}_{\text {planta }}{ }^{-1}$ de $\mathrm{K}_{2} \mathrm{O}$ (cloreto de potássio) aos oitenta dias após a poda. Na safra de inverno, para controle fitossanitário, foram realizadas pulverizações, exclusivamente com fungicidas: Metiram + Piraclostrobina ( $2 \mathrm{~kg} \mathrm{ha}^{-1}$ ) e Metalaxil-M + Mancozebe (250 g $100 \mathrm{~L}^{-1}$ ). Na safra de verão o controle foi realizado com fungicidas: Metalaxil-M + Mancozebe (250 g $\left.100 \mathrm{~L}^{-1}\right)$, Tiofanato-Metílico + Clorotalonil (200 g $\left.100 \mathrm{~L}^{-1}\right)$ e Azoxistrobina + Difenoconazol $(300 \mathrm{~mL}$ $\left.\mathrm{ha}^{-1}\right)$.

A produtividade $\left(\mathrm{kg} \mathrm{ha}^{-1}\right)$ foi obtida multiplicandose a produção da parcela formada pelo número de plantas por hectare, de acordo com o espaçamento adotado. Para o número de cachos por planta fez-se a contagem de todos os cachos da parcela. A massa de cachos foi obtida dividindo a produção por parcela pelo número de cachos. O número de bagas por cacho foi obtido da contagem de todas as bagas em quatro cachos, por parcela. O comprimento e largura dos cachos foram mensurados com paquímetro digital, em quatro cachos por parcela (Sato et al., 2009). Para avaliação do comprimento, largura e massa de baga foram coletadas dez bagas aleatoriamente, por parcela, sendo o comprimento e largura de bagas determinados com paquímetro digital. A massa de dez bagas foi determinada em balança de precisão $(0,001 \mathrm{~g})$, obtendose a média por baga.

As bagas foram destacadas dos engaços, amostrando-se, ao acaso, 10 bagas por cacho. Estas foram trituradas e o suco extraído para as determinações analíticas com três repetições, dos seguintes atributos de qualidade: teor de sólidos solúveis (SS), expresso em ${ }^{\circ}$ Brix, pH e acidez titulável (AT), expressa em g de ácido tartárico por $100 \mathrm{ml}$ de suco, conforme normas analíticas do Instituto Adolfo Lutz (2008). Calculou-se também a relação SS/AT. 
O teor de sólidos solúveis foi determinado em refratômetro digital de bancada, ajustado à temperatura ambiente. $\mathrm{O}$ potencial hidrogeniônico $(\mathrm{pH})$ foi determinado com auxílio de potenciômetro de bancada, pH digital, calibrado com soluções tampão pH 4,0 e pH 7,0. A acidez titulável foi determinada por meio de titulação, de massa conhecida (10g) do suco, com solução padronizada de hidróxido de sódio $(\mathrm{NaOH})$ a $0,1 \mathrm{~N}$, tendo como indicador solução de fenolftaleína a $1 \%$.

Os dados obtidos foram submetidos a análise de variância, em que a significância dos efeitos dos tratamentos foi determinada pelo teste F. As médias dos tratamentos (épocas de poda) foram comparadas pelo Teste de Tukey, a 5\%, e o fator concentrações de Etefon foram ajustadas por meio de análise de regressão.

\section{Resultados e Discussão}

$\mathrm{Na}$ safra de inverno as plantas foram submetidas à poda longa, com intuito de frutificação, no entanto a produtividade foi menor (Tabela 1) se comparada à safra de verão, em que as plantas foram submetidas à poda curta (poda de formação) (Tabela 4). Este fato pode ser atribuído à ocorrência de precipitação nos meses de março a maio de 2013, na safra de inverno (Figura 1), que proporcionou condições para a alta incidência de Míldio (Plasmopara viticola), afetando negativamente a floração. Situação semelhante foi relatada por Faria et al. (2004) no submédio São Francisco.

Ainda nesta safra as variáveis produtividade e número de cachos por planta foram maiores na terceira época de poda e menores na primeira época de poda (Tabela 1). Considerando o mesmo período de época de poda, Neis et al. (2010) observaram resultados semelhantes para produtividade. Trabalho com a cultivar Bordô, Malgarim et al. (2009) encontraram resultados semelhantes relatando maior número de cachos por planta, utilizando-se a poda longa. De acordo com Leão e Silva (2003) o número de cachos é um dos principais indícios da produtividade e pode ser determinado pela poda e pela fertilidade das gemas, corroborando com dados obtidos para a porcentagem de gemas brotadas na terceira época de poda $(59,50 \%)$.

$\mathrm{O}$ fato da primeira época de poda apresentar menor produtividade e número de cachos por planta pode estar relacionado à alta incidência de míldio durante a floração, afetando a formação dos cachos. Tal fato pode ser evidenciado pelas variáveis massa de cacho e número de bagas por cacho, nas quais foram observadas menores médias para esta época (Tabela 1).

Em relação às doses de Etefon na safra de inverno, foi verificado efeito significativo linear para a produtividade, evidenciando a tendência de maior dosagem para a maior produtividade (Figura 2). Esses resultados são condizentes aos obtidos por Fracaro e Boliani (2001) que observaram aumento da produção, quando da aplicação de Etefon em maiores concentrações, sobre a uva 'Rubi' em Jales-SP e obtiveram acréscimo na ordem de $31,38 \%$ sobre a produção. De acordo com Fracaro et al. (2004b) a utilização de Etefon na dose de $9 \mathrm{~L} \mathrm{ha}^{-1}$ proporcionou aumento da produtividade da uva Niágara Rosada na entressafra em Jales-SP.

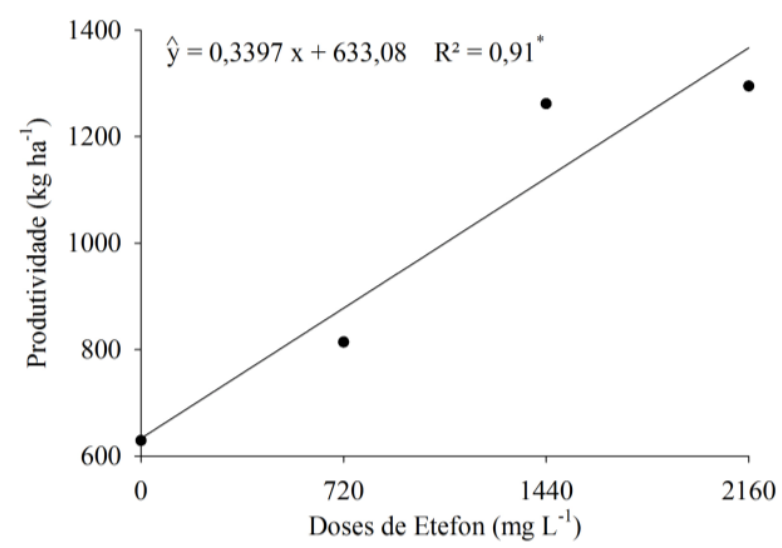

Figura 2 - Produtividade da videira 'Isabel' na safra de Inverno, submetidas a doses de Etefon.

Tabela 1. Produtividade e componentes associados à produtividade da videira Isabel na safra de Inverno, em diferentes épocas de poda submetidas a doses de Etefon: produtividade $(\mathrm{P})$, número de cachos por planta $(\mathrm{NCP})$, comprimento de cacho $(\mathrm{CC})$, largura de cacho (LC), massa de cacho (MC), e número de bagas por cacho (NBC).

\begin{tabular}{lcccccc}
\hline \multirow{2}{*}{ Tratamentos } & $\mathrm{P}$ & $\mathrm{NCP}$ & $\mathrm{CC}$ & $\mathrm{LC}$ & $\mathrm{MC}$ & $\mathrm{NBC}$ \\
\cline { 2 - 6 } & $\mathrm{kg} \mathrm{ha}^{-1}$ & cachos $^{-1}$ & $\mathrm{~mm}$ & $\mathrm{~mm}$ & $\mathrm{~g}$ & $\mathrm{bagas}^{-1}$ \\
\hline Poda (P) & & & & & & \\
$1^{\mathrm{a}}(08-03-13)$ & $356,00 \mathrm{~b}$ & $13,93 \mathrm{~b}$ & $57,56 \mathrm{~b}$ & $46,27 \mathrm{a}$ & $16,68 \mathrm{~b}$ & $9,75 \mathrm{~b}$ \\
$2^{\mathrm{a}}(22-03-13)$ & $895,30 \mathrm{ab}$ & $29,37 \mathrm{ab}$ & $65,66 \mathrm{ab}$ & $50,12 \mathrm{a}$ & $25,22 \mathrm{a}$ & $15,87 \mathrm{a}$ \\
$3^{\mathrm{a}}(05-04-13)$ & $1852,50 \mathrm{a}$ & $35,31 \mathrm{a}$ & $70,46 \mathrm{ab}$ & $45,97 \mathrm{a}$ & $29,07 \mathrm{a}$ & $15,06 \mathrm{ab}$ \\
$4^{\mathrm{a}}(19-04-13)$ & $896,00 \mathrm{ab}$ & $19,00 \mathrm{ab}$ & $77,30 \mathrm{a}$ & $47,72 \mathrm{a}$ & $27,32 \mathrm{a}$ & $13,75 \mathrm{ab}$ \\
Teste F & $5,06^{* *}$ & $4,52^{* *}$ & $4,75^{* *}$ & $1,56^{\text {ns }}$ & $8,60^{* * *}$ & $3,36^{*}$ \\
\hline DMS & 1044,72 & 17,21 & 14,37 & 5,71 & 7,06 & 5,59 \\
\hline CV $(\%)$ & 110,73 & 74,76 & 22,50 & 12,75 & 30,48 & 43,55 \\
\hline
\end{tabular}

Médias seguidas por letra diferente, na coluna, diferem entre si a $5 \%$ pelo teste de Tukey. $*$ significativo $(\mathrm{p}<0,05) ; * *$ significativo $(\mathrm{p}<0,01)$; ns não significativo. 
Para a biometria de bagas na safra de inverno apenas o diâmetro de bagas foi significativo para épocas de podas avaliadas (Tabela 2). Trabalhando com épocas de poda na cultivar Patrícia em Silvânia-GO, Silva et al. (2006) verificaram para o diâmetro das bagas, que a poda de 27/04 foi a única que diferiu significativamente, com média de 19,14 mm de diâmetro. Sato et al. (2009) não observaram resultados significativos para massa e diâmetro das bagas para cultivar Isabel sobre diferentes porta-enxertos na Região Norte do Paraná. Com relação às doses de Etefon não foi constatado resultados significativos, na safra inverno, para os resultados de biometria de bagas.

Foram observadas diferenças significativas para todas as características qualitativas da uva Isabel, na safra de inverno (Tabela 3). De modo geral a terceira época de poda se destacou apresentando melhores índices de qualidade em conjunto, entretanto não diferiu de outras épocas de poda dentre as variáveis estudadas. Resultados semelhantes foram constatados por Silva et al. (2006) em estudo de comportamento fenológico da cultivar Patrícia em diferentes épocas de podas; foi verificado valor de $18,87^{\circ}$ Brix para a poda realizada em 27 de abril.

Em estudo com diferentes épocas de poda na videira Niágara rosada, na região de Santa Rita do Araguaia-
GO, Martins et al. (2014) verificaram que apenas a poda E8 (26/04/2008) apresentou média de teor de sólidos solúveis dentro das normas de exportação cujo mínimo é de 16,5 ${ }^{\circ}$ Brix. Por outro lado, Neis et al. (2010) em estudos com a videira Niágara rosada, não observaram diferenças significativas entre as quatro épocas de poda, para a variável sólidos solúveis.

Os valores encontrados de sólidos solúveis para as quatros épocas de poda ficaram nos padrões exigidos pela Legislação Brasileira (Brasil, 2000), em que o teor mínimo exigido é de $14{ }^{\circ}$ Brix. O menor valor observado foi para a primeira época de poda $14,42{ }^{\circ}$ Brix, fato este que pode estar associado à alta desfolha causada pela incidência de Míldio. É importante ressaltar que na quarta época de poda, houve ataque de maribondos (Euscorpius sp.) nos frutos, fato que antecipou a época de colheita interferindo no baixo teor de sólidos solúveis.

Segundo Rizzon e Meneguzzo (2007), entre as cultivares do grupo das americanas, a cultivar Isabel apresenta elevado potencial de acúmulo de açúcar na baga, podendo variar, em função das safras, entre 14 ${ }^{\circ}$ Brix a $18{ }^{\circ}$ Brix. De maneira geral, na medida em que há evolução da maturação da uva, há tendência ao incremento do conteúdo de sólidos solúveis e redução da acidez.

Tabela 2. Biometria de bagas da uva Isabel, na safra de inverno, em diferentes épocas de poda e submetidas à doses de Etefon.

\begin{tabular}{|c|c|c|c|}
\hline Tratamentos & Comprimento (mm) & Diâmetro (mm) & Massa (g) \\
\hline \multicolumn{4}{|l|}{ Poda $(\mathrm{P})$} \\
\hline $1^{\mathrm{a}}(08-03-13)$ & $17,47 \mathrm{a}$ & $15,14 \mathrm{ab}$ & $3,28 \mathrm{a}$ \\
\hline $2^{a}(22-03-13)$ & $17,33 \mathrm{a}$ & $15,75 \mathrm{a}$ & $3,24 \mathrm{a}$ \\
\hline $3^{a}(05-04-13)$ & $17,31 \mathrm{a}$ & $15,00 \mathrm{~b}$ & $3,08 \mathrm{a}$ \\
\hline $4^{a}(19-04-13)$ & $17,29 \mathrm{a}$ & $15,35 \mathrm{ab}$ & $3,21 \mathrm{a}$ \\
\hline Teste F & $0,18^{\mathrm{ns}}$ & $2,72^{*}$ & $0,22^{\mathrm{ns}}$ \\
\hline DMS & 0,70 & 0,74 & 0,68 \\
\hline CV (\%) & 4,30 & 5,14 & 22,56 \\
\hline
\end{tabular}

Médias seguidas por letra diferente, na coluna, diferem entre si a 5\% pelo teste de Tukey. * significativo (p<0,05); ns - não significativo.

Tabela 3. Características qualitativas da uva Isabel, na safra de Inverno, em diferentes épocas de poda submetidas a doses de Etefon.

\begin{tabular}{|c|c|c|c|c|}
\hline \multirow[b]{2}{*}{ Tratamentos } & Sólidos solúveis & $\mathrm{pH}$ & Acidez titulável & SS/AT \\
\hline & ${ }^{\circ}$ Brix & \multicolumn{3}{|c|}{$\begin{array}{c}\text { (g de ácido tartárico por } \\
100 \mathrm{ml}^{-1} \text { de suco) }\end{array}$} \\
\hline \multicolumn{5}{|l|}{ Poda (P) } \\
\hline $1^{\mathrm{a}}(08-03-13)$ & $14,42 \mathrm{c}$ & $3,04 \mathrm{c}$ & $0,92 a b$ & $16,15 \mathrm{c}$ \\
\hline $2^{a}(22-03-13)$ & $18,49 \mathrm{a}$ & $3,25 \mathrm{~b}$ & $0,93 \mathrm{ab}$ & $20,02 \mathrm{ab}$ \\
\hline $3^{a}(05-04-13)$ & $18,80 \mathrm{a}$ & $3,13 \mathrm{c}$ & $0,83 \mathrm{~b}$ & 22,80 a \\
\hline $4^{a}(19-04-13)$ & $15,97 \mathrm{~b}$ & $3,58 \mathrm{a}$ & $0,99 \mathrm{a}$ & $16,89 \mathrm{bc}$ \\
\hline Teste F & $29,29^{* *}$ & $82,56^{* *}$ & $2,88^{*}$ & $10,21^{\text {*** }}$ \\
\hline DMS & 1,45 & 0,09 & 0,14 & 3,61 \\
\hline $\mathrm{CV}(\%)$ & 9,14 & 3,49 & 16,41 & 20,18 \\
\hline
\end{tabular}

Médias seguidas por letra diferente, na coluna, diferem entre si a 5\% pelo teste de Tukey. * significativo (p < 0,05); ** significativo (p < 0,01); ns não significativo; Q - modelo quadrático. 
De acordo com Sato et al. (2009), o índice de maturação (SS/AT) pode ser uma boa opção para se determinar o ponto ideal de colheita das uvas, representando um equilíbrio entre o teor de açúcar e a acidez. A avaliação dos ácidos orgânicos é um critério de grande importância e bastante utilizado na determinação do ponto de colheita de uvas destinadas à elaboração de vinhos. Realizado conjuntamente com a análise do teor de açúcares, a avaliação da acidez total possibilita uma observação mais ampla da relação açúcares/acidez, critério este mais confiável na determinação da qualidade geral da uva possibilitando, assim, estabelecer o momento ideal para colheita (Guerra et al., 2003).

Quanto à acidez titulável da safra de inverno foram observados valores satisfatórios para elaboração de subprodutos da uva (Tabela 3). Nessa safra, independente da época de poda, a acidez titulável atingiu valores acima de $0,5 \mathrm{~g}$ de ácido tartárico por 100 $\mathrm{ml}^{-1}$ de suco; valores padrão indicados por Guerra et al. (2003). Segundo o autor, uvas destinadas à elaboração de suco devem apresentar acidez titulável entre 0,5 e 0,9 g de ácido tartárico por $100 \mathrm{ml}^{-1}$ de suco para que sejam produzidos sucos de boa qualidade. Para o índice de maturação SS/AT, as quatro épocas de poda obtiveram valores satisfatórios também para o consumo in natura, conforme Camargo (1994) que atribui uma faixa aceitável na relação SS/AT para o consumo de uvas de mesa, no mínimo, entre 15 e 16.

Através da análise de regressão, não foi observado efeito significativo das doses de Etefon sobre o teor de sólidos solúveis. Resultados semelhantes foram encontrados por Rodrigues et al. (2010) que ao estudarem o efeito do Etefon na videira Rubi não constataram diferença para o teor de sólidos solúveis. Pereira e Fracaro (2004) também chegaram às mesmas conclusões para a videira 'Niágara rosada'.

Com relação às doses de Etefon houve resultado significativo para a variável acidez titulável e $\mathrm{pH}$, na safra de inverno, sendo que o aumento da dosagem, até $1440 \mathrm{mg} \mathrm{L}^{-1}$ de Etefon, proporcionou a diminuição da acidez titulável e elevação do pH (Figura 3). Estes resultados corroboram com os obtidos por Pereira e Fracaro (2004) que observaram tendência de diminuição da acidez titulável com o aumento da concentração de Etefon, embora os índices obtidos estivessem normalmente acima do nível mínimo aceitável para comercialização de $0,5 \mathrm{~g}$ de ácido tartárico por 100 gramas de polpa.

$\mathrm{Na}$ safra de verão, verificou-se que a segunda época de poda obteve melhor desempenho, sendo a produtividade mais elevada com $9046 \mathrm{~kg} \mathrm{ha}^{-1}$, maior comprimento de cacho, massa de cacho e quantidade de bagas por cacho, em relação às outras épocas de poda (Tabela 4). Avaliando a cultivar Isabel na Região Norte do Paraná Sato et al. (2008) observaram a média da massa e do comprimento dos cachos de $125,1 \mathrm{~g}$ e 11,6 $\mathrm{cm}$, respectivamente.

Não foi constatada diferença significativa para as doses de Etefon na safra de verão, não afetando comercialmente as variáveis estudadas.

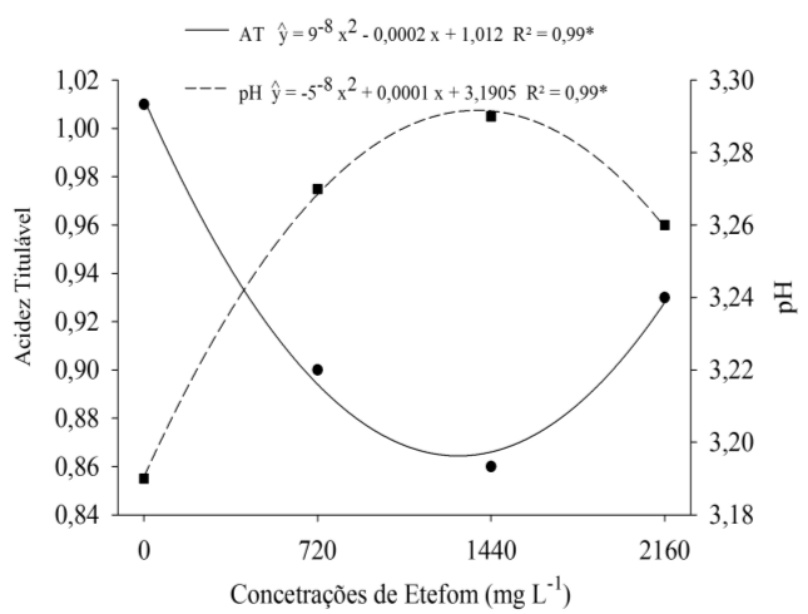

Figura 3 - Acidez titulável (g de ácido tartárico por $100 \mathrm{~mL}^{-1}$ de suco) e pH da uva Isabel na safra de Inverno, submetidas a doses de Etefon.

Tabela 4 - Produtividade e componentes associados à produtividade da videira Isabel na safra de verão, em diferentes épocas de poda submetidas a doses de Etefon: produtividade $(\mathrm{P})$, número de cachos por planta $(\mathrm{NCP})$, comprimento de cacho $(\mathrm{CC})$, largura de cacho (LC), massa de cacho (MC), e número de bagas por cacho (NBC).

\begin{tabular}{ccccccc}
\hline Tratamentos & $\mathrm{P}$ & $\mathrm{NCP}$ & $\mathrm{CC}$ & $\mathrm{LC}$ & $\mathrm{MC}$ & $\mathrm{NBC}$ \\
\cline { 2 - 7 } & $\mathrm{kg} \mathrm{ha}^{-1}$ & cachos $^{-1}$ & $\mathrm{~mm}$ & $\mathrm{~mm}$ & $\mathrm{~g}$ & $\mathrm{bagas}^{-1}$ \\
\hline Poda (P) & & & & & & \\
$1^{\mathrm{a}}(08-03-13)$ & $5.060,66 \mathrm{~b}$ & $51,56 \mathrm{a}$ & $86,73 \mathrm{ab}$ & $57,62 \mathrm{a}$ & $58,10 \mathrm{~b}$ & $20,18 \mathrm{~b}$ \\
$2^{\mathrm{a}}(22-03-13)$ & $9.682,70 \mathrm{a}$ & $60,68 \mathrm{a}$ & $95,95 \mathrm{a}$ & $61,72 \mathrm{a}$ & $87,42 \mathrm{a}$ & $24,21 \mathrm{a}$ \\
$3^{\mathrm{a}}(05-04-13)$ & $3.945,00 \mathrm{~b}$ & $42,62 \mathrm{a}$ & $80,17 \mathrm{~b}$ & $57,96 \mathrm{a}$ & $49,57 \mathrm{~b}$ & $18,59 \mathrm{~b}$ \\
$4^{\mathrm{a}}(19-04-13)$ & $5.546,50 \mathrm{~b}$ & $57,12 \mathrm{a}$ & $86,44 \mathrm{ab}$ & $58,73 \mathrm{a}$ & $50,88 \mathrm{~b}$ & $21,03 \mathrm{ab}$ \\
Teste F & $7,21^{* * *}$ & $1,93^{\text {ns }}$ & $4,98^{* *}$ & $2,61^{\mathrm{ns}}$ & $16,99^{* *}$ & $5,75^{* *}$ \\
\hline DMS & 3524,57 & 27,22 & 10,98 & 4,36 & 16,92 & 3,72 \\
\hline CV $(\%)$ & 61,66 & 54,45 & 13,34 & 7,83 & 27,91 & 18,80 \\
\hline
\end{tabular}

Médias seguidas por letra diferente, na coluna, diferem entre si a 5\% pelo teste de Tukey. ** significativo (p < 0,01); ns - não significativo. 
Avaliando épocas de poda, na videira Niágara rosada, Martins et al. (2014) relatam produção acima de $11 \mathrm{~kg}$ planta $^{-1}$ e produtividade de $9 \mathrm{Mg} \mathrm{ha}^{-1}$, sendo que a menor produção foi registrada para a época de poda (E3) realizada em 01 de fevereiro de 2008 com 4,64 kg planta $^{-1}$ e produtividade de 3,86 $\mathrm{Mg} \mathrm{ha}^{-1}$. Segundo o mesmo autor a produtividade da uva está associada a um número considerável de fatores, entre eles o potencial genético da variedade, o padrão tecnológico utilizado, a idade do parreiral, as condições climáticas, o estado fitossanitário, entre outros.

Na safra de verão o comprimento e diâmetro de baga na segunda, terceira e quarta época de poda não diferiram entre si, sendo que a primeira época de poda apresentou resultado significativamente menor (Tabela 5). Contudo os resultados mostram que para safra de verão, as variáveis de biometria das bagas obtiveram melhores médias se comparadas com a safra de inverno, corroborando com a literatura Camargo (2004) que registraram para a cultivar Isabel média de $17,2 \mathrm{~cm}$ de diâmetro e $18,7 \mathrm{~cm}$ de comprimento.

Com relação às doses de Etefon não foram constados resultados significativos para a variável biometria de bagas, na safra de verão.

Observa-se na Tabela 6, para as características qualitativas da uva Isabel na safra de verão, diferença significativa para todas as épocas de poda. A variável sólidos solúveis na segunda e terceira épocas de poda diferiram das demais épocas, entretanto os valores não foram satisfatórios para os padrões exigidos pela Legislação Brasileira (Brasil, 2000).

Verificado no experimento, pode-se associar o baixo teor de sólidos solúveis, menor que $14{ }^{\circ}$ Brix, ao desfolhamento ocorrido nas videiras em virtude da alta incidência de míldio. De acordo Brighenti et al. (2010), o teor de sólidos solúveis nas uvas está associado à maior atividade fotossintética, derivada do aumento da área foliar da videira. Segundo Zalamena et al. (2013) em certas situações, a desfolha ao redor dos cachos pode retardar a maturação, pois o menor número de folhas por planta causa a diminuição da produção de fotoassimilados para os cachos, conforme relatado por Pötter et al. (2010), o que reduziria o $\mathrm{pH}$ e aumentaria o teor de acidez total no mosto.

Segundo Miele e Rizzon (2013), os principais açúcares da uva, glicose e frutose, são sintetizados na folha da videira pelo processo da fotossíntese, e sua concentração no fruto depende de fatores diversos. A área foliar, especialmente de folhas expostas ao sol, é um importante fator para a produção desses açúcares e sua acumulação na uva. Dessa forma, a elevada incidência de doenças fúngicas decorrentes do excesso de água no solo (na época da colheita da safra de verão) e de outros fatores climáticos impedem que a uva atinja a completa maturação, comprometendo a sua qualidade (Regina et al., 2006).

Tabela 5. Biometria de bagas de uva Isabel, na safra de verão, em diferentes épocas de poda submetidas a doses de Etefon.

\begin{tabular}{|c|c|c|c|}
\hline Tratamentos & Comprimento $(\mathrm{mm})$ & Diâmetro (mm) & Massa (g) \\
\hline \multicolumn{4}{|l|}{ Poda $(\mathrm{P})$} \\
\hline $1^{a}(08-03-13)$ & $18,49 \mathrm{~b}$ & $16,62 \mathrm{~b}$ & $36,71 \mathrm{~b}$ \\
\hline $2^{a}(22-03-13)$ & $19,77 \mathrm{a}$ & $17,48 \mathrm{a}$ & $42,96 \mathrm{a}$ \\
\hline $3^{\mathrm{a}}(05-04-13)$ & $19,54 \mathrm{a}$ & $17,49 \mathrm{a}$ & $41,67 \mathrm{a}$ \\
\hline $4^{a}(19-04-13)$ & $19,29 \mathrm{a}$ & $17,73 \mathrm{a}$ & $40,28 \mathrm{ab}$ \\
\hline Teste F & $10,84^{* *}$ & $6,85^{* *}$ & $7,41^{* *}$ \\
\hline DMS & 0,63 & 0,70 & 3,73 \\
\hline $\mathrm{CV}(\%)$ & 3,50 & 4,32 & 9,80 \\
\hline
\end{tabular}

Médias seguidas por letra diferente, na coluna, diferem entre si a 5\% pelo teste de Tukey. ** significativo (p <0,01); ns - não significativo.

Tabela 6. Características qualitativas da uva Isabel, na safra de verão, em diferentes épocas de poda submetidas a doses de Etefon

\begin{tabular}{|c|c|c|c|c|}
\hline \multirow[b]{2}{*}{ Tratamentos } & Sólidos solúveis & $\mathrm{pH}$ & Acidez titulável & SS/AT \\
\hline & ${ }^{\circ}$ Brix & \multicolumn{3}{|c|}{$\begin{array}{l}\text { (g de ácido tartárico por } \\
100 \mathrm{~mL} \text { de suco) }\end{array}$} \\
\hline \multicolumn{5}{|l|}{ Poda (P) } \\
\hline $1^{\mathrm{a}}(08-03-13)$ & $13,17 \mathrm{ab}$ & $2,53 \mathrm{~b}$ & $0,89 \mathrm{a}$ & $14,91 \mathrm{~b}$ \\
\hline $2^{\mathrm{a}}(22-03-13)$ & $13,92 \mathrm{a}$ & $2,40 \mathrm{c}$ & $0,77 \mathrm{~b}$ & $18,04 \mathrm{a}$ \\
\hline $3^{\mathrm{a}}(05-04-13)$ & $13,35 \mathrm{a}$ & $2,48 \mathrm{~b}$ & $0,78 \mathrm{~b}$ & $17,28 \mathrm{a}$ \\
\hline $4^{a}(19-04-13)$ & $12,34 \mathrm{~b}$ & $2,70 \mathrm{a}$ & $0,83 \mathrm{ab}$ & $14,85 \mathrm{~b}$ \\
\hline Teste F & $6,59^{* *}$ & $37,59^{* *}$ & $9,18^{* *}$ & $9,92^{* *}$ \\
\hline DMS & 0,95 & 0,07 & 0,06 & 1,95 \\
\hline $\mathrm{CV}(\%)$ & 7,68 & 3,26 & 8,88 & 12,76 \\
\hline
\end{tabular}

Médias seguidas por letra diferente, na coluna, diferem entre si a $5 \%$ pelo teste de Tukey. ${ }^{* *}$ significativo $(\mathrm{p}<0,01)$; ns- não significativo. 
A legislação brasileira estabelece os limites da relação SS/AT entre 15 e 45 que seria o índice maturação (Brasil, 2000). Os valores mais elevados representam sucos de uva menos ácidos. Neste estudo a relação mais alta atingida foi para a segunda e terceira época de poda com 18,04 e 17,28, indicando que as uvas estavam aptas para a produção de suco de uva e para consumo in natura.

Visto que é necessária a presença de folha para que o Etefon possa ser absorvido, o resultado da aplicação do produto nesse experimento pode ter sido comprometido pelo baixo índice foliar observado nas videiras, em função da alta incidência de míldio da safra anterior (safra de inverno). Segundo Fracaro et al. (2004a) a aplicação de Etefon deve estar associada ao uso adequado de outras práticas no parreiral, principalmente de manejo, adubação e controle fitossanitário, para que a produção seja otimizada em regiões tropicais e subtropicais do Brasil.

\section{Conclusões}

Na safra de inverno a poda realizada em 05 de abril alcançou a maior produtividade e melhor qualidade. A produtividade apresentou crescimento linear, sob aplicação de doses de Etefon até $2.160 \mathrm{mg} \mathrm{L}^{-1}$.

$\mathrm{Na}$ safra de verão a poda de 22 de março alcançou maior produtividade e melhor qualidade de frutos. As doses de Etefon não influenciaram a produtividade e qualidade dos frutos, para esta safra.

\section{Referências Bibliográficas}

BARDIN, L., PEDRO JÚNIOR, M. J., MORAES, J. F. L., PEDRO, F. G. Estimativas das épocas de colheita da videira 'Niágara rosada' na região do polo turístico do circuito das frutas, São Paulo. Scientia Agraria, Curitiba-PR, v. 11, n. 2, p. 135-139, 2010.

BOUBAKRI, H.; WAHAB, M. A.; CHONG, J.; BERTSCH, C.; MLIKI, A.; SOUSTRE-GACOUGNOLLE, I. Thiamine induced resistance to Plasmopara viticola in grapevine and elicited hostedefense responses, including HR like-cell death. Plant Physiology and Biochemistry, v. 57, p. 120-133, 2012.

BRASIL-MAPA. MINISTÉRIO DA AGRICULTURA E DO ABASTECIMENTO. Instrução Normativa n. 01, de 07 de janeiro de 2000. Regulamento técnico geral para fixação dos padrões de identidade e qualidade para polpa de fruta. Diário Oficial da República Federativa do Brasil, Brasília, DF, 10 jan. 2000, Seção 1, p. 54-58.

BRIGHENTI, A. F.; RUFATO, L.; KRETZSCHMAR, A. A.; MADEIRA, F. C. Desponte dos ramos da videira e seu efeito na qualidade dos frutos de 'Merlot' sobre os porta-enxertos 'Paulsen 1103' e 'Couderc 3309'. Revista Brasileira de Fruticultura, Jaboticabal-SP, v. 32, n. 1, p. 19-26, 2010.

CAMARGO, U. A. Uvas do Brasil. Bento Gonçalves-RS: Embrapa Uva e Vinho, 1994. 90 p. (Documento, 9).
CAMARGO, U.A. 'Isabel Precoce': Alternativa para a Vitivinicultura Brasileira. Bento Gonçalves-RS: Embrapa Uva e Vinho, 2004. 6p. (Comunicado Técnico, 54)

CAMARGO, U. A., PROTAS, J. F. S. Vitivinicultura brasileira: panorama setorial de 2010. SEBRAE. Brasília-DF: IBRAVIN, Embrapa Uva e Vinho, Bento Gonçalves-RS, 2011. $110 \mathrm{p}$

CAMARGO, U. A., TONIETTO, J., HOFFMANN, A. Progressos na viticultura brasileira. Revista Brasileira de Fruticultura, Jaboticabal-SP, v. 33, n. especial, p. 144-149, 2011.

EMBRAPA. EMPRESA BRASILEIRA DE PESQUISA AGROPECUÁRIA. Sistema brasileiro de classificação de solos. $3^{\text {a }}$ ed. Brasília-DF: Embrapa, 353 p. 2013.

FARIA, C. M. B.; SOARES, J. M.; LEÃO, P. C. S. Adubação verde com leguminosas em videira no Submédio São Francisco. Revista Brasileira de Ciência do Solo, ViçosaMG, v. 28, n. 4, p. 641-648, 2004.

FRACARO, A. A.; BOLIANI, A. C. Efeito do Ethephon em videira 'Rubi' (Vitis vinifera $\mathrm{L}$.), cultivada na região noroeste do estado de São Paulo. Revista Brasileira de Fruticultura, Jaboticabal-SP, v. 23, n. 3, p. 510-512, 2001.

FRACARO, A. A.; PEREIRA, F. M.; NACHTIGAL, J. C. Uso do Ethephon antes da poda de produção em videira Niágara rosada' (Vitis labrusca L.). Revista Brasileira de Fruticultura, Jaboticabal-SP, v. 26, n. 1, p. 97-100, 2004a.

FRACARO, A. A.; PEREIRA, F. M.; NACHTIGAL, J. C.; BARBOSA, J. C. Efeito do Ethephon sobre a produção da uva 'Niágara Rosada' (Vitis labrusca L.), produzida na entressafra na região de Jales-SP. Revista Brasileira de Fruticultura, Jaboticabal-SP, v. 26, n. 1, p. 82-85, 2004b.

GUERRA, C. C.; SILVA, G. A.; TONIETTO, J.; MELLO, L. M. R. Uva para processamento: pós-colheita. Bento Gonçalves-RS: Embrapa Uva e Vinho - Informação Tecnológica, 2003. 67 p. (Frutas do Brasil; 36)

IBGE. INSTITUTO BRASILEIRO DE GEOGRAFIA E ESTATÍSTICA. Levantamento Sistemático da Produção Agrícola. 2016. Disponível em: http://www.sidra.ibge.gov.br/bda/tabela/listabl.asp?c=188\&n= $0 \& \mathrm{u}=0 \& \mathrm{z}=\mathrm{t} \& \mathrm{o}=26 \& \mathrm{i}=\mathrm{P}$. Acesso em: 03 de ago. 2016.

IAL. INSTITUTO ADOLFO LUTZ. Métodos físicoquímicos para análise de alimentos. (Coord.: ZENEBON, O., PASCUET, N.S., TIGLEA, P.) 4a . ed. São Paulo-SP: Instituto Adolfo Lutz, 1020 p., 2008.

LEÃO, P. C. S.; SILVA, E. E. G. Brotação e fertilidades de gemas em uvas sem sementes no Vale do São Francisco. Revista Brasileira de Fruticultura, Jaboticabal-SP, v.25, n.3, p. $375-378,2003$.

MALGARIM, M. B.; AFINOVICZ, A. P.; EULEUTERIO, M. D.; PIERIN, F. F.; DIAS, J. S.; SOZIM, M. Diferentes tipos de poda na produção da videira cv. Bordô. Semina, LondrinaPR, v. 30, supl. 1, p. 1203-1206, 2009.

MARTINS, W. A.; SANTOS, S. C.; SMILJANIC, K. B. A. Exigência térmica e produção da videira Niágara Rosada em 
diferentes épocas de poda no Cerrado do Brasil. Revista de Ciências Agrárias, Lisboa, v. 37, n. 2, p. 171-178, 2014.

MIELE, A.; RIZZON, L. A. Intensidades da poda seca e do desbaste de cacho na composição da uva Cabernet Sauvignon. Revista Brasileira de Fruticultura, Jaboticabal-SP, v. 35, n. 4, p. 1081-1092, 2013.

NEIS, S.; REIS, E. F. SANTOS, S. C. Produção e qualidade da videira cv. Niágara rosada em diferentes épocas de poda no sudoeste goiano. Revista Brasileira de Fruticultura, Jaboticabal-SP, v. 32, n. 4, p. 1146-1153, 2010.

PEREIRA, F. M.; FRACARO, A. A. Efeito do ethephon na qualidade da uva 'Niágara Rosada' (Vitis labrusca L.), produzida na entressafra, na região de Jales-SP. Revista Brasileira de Fruticultura, Jaboticabal-SP, v. 32, n. 2, p. 254-257, 2004

PÖTTER, G. H.; DAUDT, C. E.; BRACKAMNN, A.; LEITE, T. T.; PENNA, N. G. Desfolha parcial em videiras e seus efeitos em uvas e vinhos Cabernet Sauvignon da região da Campanha do Rio Grande do Sul, Brasil. Ciência Rural, Santa Maria-RS, v. 40, n. 9, p. 2011-2016, 2010.

REGINA, M. A.; AMORIM, D. A.; FAVERO, A. C.; MOTA, R. V.; RODRIGUES, D. J. Novos pólos vitícolas para produção de vinhos finos em Minas Gerais. Informe Agropecuário, Belo Horizonte-MG, v. 27, n. 234, p. 111-118, 2006.

RIZZON, L. A.; MENEGUZZO, J. Suco de uva. Brasília-DF: Embrapa Informação Tecnológica, 2007. 45 p.

RODRIGUES, A.; GIRARDI, E. A.; FILHO. J. A. S. Aplicação de Ethephon e qualidade da uva 'Rubi' em Porto Feliz-SP. Revista Brasileira de Fruticultura, Jaboticabal-SP, v. 32, n. 3, p. 925-930, 2010.
SATO, A. J.; SILVA, B. J.; SANTOS, C. E.; BERTOLUCCI, R.; SANTOS, R.; CARIELO, M.; GUIRAUD, M. C.; FONSECA, I. C. B.; ROBERTO, S. R. Fenologia e demanda térmica das videiras 'Isabel' e 'Rubea' sobre diferentes portaenxertos na Região Norte do Paraná. Semina, Londrina-PR, v. 29, n. 2, p. 283-292, 2008.

SATO, A. J.; SILVA, B. J.; BERTOLUCCI, R.; CARIELO, M.; GUIRAUD, M. C.; FONSECA, I. C. B.; ROBERTO, S. R. Evolução da maturação e características físico-químicas de uvas da cultivar Isabel sobre diferentes porta-enxertos na Região Norte do Paraná. Semina, Londrina-PR, v. 30, n. 1, p. 11-20, 2009.

SCHENATO, P.G., MELO, G.W., SANTOS, H.P., FIALHO, F.B., FURLANETTO, V., BRUNETTO, G., DORNELES, L. T. Influência do Etefon na distribuição de nutrientes e carboidratos e sobre o crescimento em videiras jovens. Revista Brasileira de Fruticultura, Jaboticabal-SP, v. 29, n. 2, p. 217-221, 2007.

SILVA, R. P., DANTAS, G. G., NAVES, R. V., CUNHA, M. G. Comportamento Fenológico de videira, cultivar Patrícia em diferentes épocas de poda de frutificação em Goiás. Bragantia, Campinas-SP, v. 65, n. 3, p. 399-406, 2006.

ZALAMENA, J.; CASSOL, P. C.; BRUNETTO, G.; PANISSON, J.; MARCON FILHO, J. L.; SCHLEMPER, C. Produtividade e composição de uva e de vinho de videiras consorciadas com plantas de cobertura. Pesquisa Agropecuária Brasileira, Brasília-DF, v. 48, n. 2, p. 182-189, 2013. 